\title{
Modeling hydrological impacts of groundwater level in the context of climate and land cover change
}

\author{
Ray-Shyan $\mathrm{Wu}^{1}$ and Dong-Sin Shih ${ }^{2, *}$ \\ ${ }^{1}$ Department of Civil Engineering, National Central University, Taoyuan City, Taiwan \\ ${ }^{2}$ Department of Civil Engineering, National Chung Hsing University, Taichung City, Taiwan
}

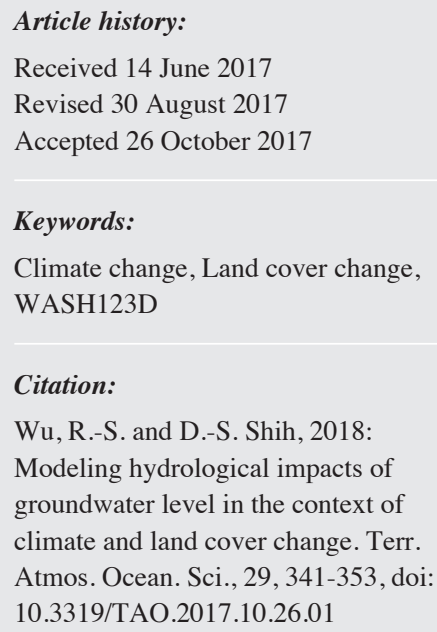

\begin{abstract}
The study uses weather generation models to generate future daily rainfall and temperature, and incorporates a land coverage model to simulate future land use changes. These future scenarios are then simulated by a rainfall runoff model to study their impacts on basin discharge, river, and groundwater levels. The Fengshan Creek basin in northern Taiwan is selected as test site. The RCP2.6 scenario is adopted to project future climate. The hydrological impacts, in the context of groundwater, for the near future (2020 - 2039), future (2050 - 2069), and distant future (2080 - 2099) are discussed. Simulations indicate that the influence of climate change is more important compared to local land cover changes at our study site. Both river stage and groundwater levels are influenced under future scenarios, but seasonally rather than annually; the dry and wet seasons are amplified. The results indicate that future water resources will be scarce in the dry season and more abundant in the wet season. In addition, changes in groundwater levels for mountainous region are more significant than in the downstream flat areas.
\end{abstract}

\section{INTRODUCTION}

Global climate change will result in increases in mean air temperature and changes in precipitation, affecting temporal and spatial availability of water resources, with increasing extreme rainstorms and drought (IPCC 2008). Based on the Working Group I contribution to the Fifth Assessment Report (AR5) of the Intergovernmental Panel on Climate Change, global temperatures have warmed an average of $0.85^{\circ} \mathrm{C}(0.65-1.06)$ from 1880 to 2012 , as evidenced from multiple independently produced datasets (Climate Change 2013, The Physical Science Basis, Summary for Policymakers 2013; IPCC 2013). However, the intensity and frequency of heavy rainfall have increased globally and are seasonally exacerbated: rainy seasons are wetter and dry seasons are drier. Stream flow and groundwater recharge is particularly influenced during the wet and dry seasons. For instance, average global extreme flood losses in 2005 were estimated as approximately $\$ 6$ billion per year, which is projected to increase to $\$ 52$ billion by 2050 with socioeconomic changes (Hallegatte et al. 2013).

\footnotetext{
* Corresponding author

E-mail:dsshih@nchu.edu.tw
}

Climate change alters the risk of hydrological extremes on regional scales, and the hydrological response of a catchment can vary substantially due to location and specific catchment characteristics (Veijalainen et al. 2010; Yang et al. 2015). Recent studies have found that climate change affects local rainfall amounts, surface runoff, and distribution of water resources (Guo et al. 2002; Akhtar et al. 2008; Arnell and Gosling 2013; Kling et al. 2014). Climate change is characterized by shifts in temperature and precipitation, with regionally specific responses, e.g., alteration of extremes, intensities, frequencies, and spatial and temporal patterns (Easterling et al. 2000; Hay et al. 2011; Wang et al. 2013; Hovenga et al. 2016). Hovenga et al. (2016) addressed the effects of climate change on overland processes, river inflow, and sediment loading for the Apalachicola River region in Florida, USA. Within the wet seasons, the A1B scenario had the largest loadings and A2 was typically largest during the dry season. In the same region, Chen et al. (2014) indicated that the seasonal responses of runoff and sediment loads were slight with contrasting behaviors between different models.

In Taiwan, statistical data shows that the warming rate 
was about $0.14^{\circ} \mathrm{C}$ per ten years from 1911 to 2009 (Hsu et al. 2011). This increase in temperature is higher than the global average. In recent decades, extreme typhoon-induced floods have occurred all over Taiwan. Rising sea levels have induced storm surges, seawater intrusions, and even land salinization, all of which affect our living environment (Shih et al. 2012b; Hsu et al. 2015). To confront the effects of climate change in the future, land use planning has become one of the most important challenges in Taiwan. One of the strongest influences on Taiwan's hydrological environment resulting from climate change is water resource distribution (Tung 2001). A decrease in medium- and lowintensity rainfall may lead to insufficient water content in the soil and in groundwater, resulting in drought scenarios. Therefore, variations in hydrological environments influence the stability of water supply, and will result in difficult operating water and tend to undersupply of water resources. In addition, extremely heavy rainfall results in flood-related disasters in low-lying areas, and worsens debris flow disasters due to hillside debris avalanches (Shih et al. 2012b).

To better understand the effects of climate and land cover changes on basin hydrology, this study proposes a method to evaluate effects of future climate and land coverage using the Weather Generator (WGEN) model, General Circulation Models (GCMs), and Conversion of Land Use and its Effects over Small Regions model (CLUE-s). To relieve computational burden on implementing the WASH123D (WAterSHed Systems of 1-D Stream-River Network, 2-D Overland Regime, and 3-D Subsurface Media, Yeh et al. 1998) simulations to the downstream subsurface of Fengshan Creek basin, the Hydrologic Modeling System (HEC-HMS) is applied to simulate runoffs, and the flow distribution in a watershed is modeled using the WASH123D numerical model. Climate scenarios generated from GCMs or Regional Climate Models (RCMs) are one of the most common approaches to estimating future water distribution and movement (Menzel et al. 2006; Déqué et al. 2007; Minville et al. 2008; Prudhomme and Davies 2008). Applications of CLUE-s land cover modeling have ranged in scale from small regions to entire continents (Verburg et al. 2006a, b; Lin et al. 2007; Wassenaar et al. 2007; Hurkmans et al. 2009; Trisurat et al. 2010; Britz et al. 2011; Park et al. 2011). Moreover, the HEC-HMS is selected as the appropriate protocol to conduct rainfall runoff simulation because it is widely used and freely available. The HECHMS model has proven reliable and applicable for many hydrological simulations (Halwatura and Najim 2013). The WASH123D model has been recently applied to several regionally significant projects, e.g., The Comprehensive Everglades Restoration Plan (CERP) and Regional Engineering Model for Ecosystem Restoration (REMER) projects. The model was also chosen by the U.S. Army Corps as the core computational code to model the Lower East Coast (LEC) wetland watershed (Yeh et al. 2011). An improved version of WASH123D model has been developed and applied to many river basins in Taiwan for studies of hydrological hazards (Shih and Yeh 2011; Shih et al. 2012a, b; Hsu et al. 2015). Therefore, this study integrated aforementioned climate and land cover changes with watershed models in a new modeling procedure.

\section{METHODOLOGY}

\subsection{Weather Generator (WGEN) and Land Cover Models}

In this study, the WGEN model was applied to generate future daily precipitation and temperature with climate scenarios. Weather generators based on either Markov chains (Richardson 1981) or empirical distributions of wet/ dry spells (Semenov and Brooks 1999) are commonly used. The downscaled data of the IPCC RCP2.6 scenario adopted in this study was provided by the Taiwan Climate Change Projection and Information Platform (TCCIP 2015). Projected changes in future temperature and precipitation are taken into calculations to obtain the ensemble mean of 24 GCMs. Daily temperature is generated using monthly mean and daily records, assuming temperature time series as the first-order Markov Chain process (Pickering et al. 1988; Wu and Haith 1993). Daily temperature is expressed as the function of monthly mean and standard deviation, and a random variable is used to generate an extraordinary occurrence. Rainfall event identification is determined based on historical rainfall probability. The Markov chain process, using historical records and a random variable, is applied to identify a rainfall event. First, a day is identified as rainy or rainless, and then the amount of rainfall is estimated for a rainfall occurrence using an exponential distribution. As a result, near future (2020 - 2039 years), future (2050 - 2069 years), and distant future (2080 - 2099 years) temperature and precipitation scenarios are generated.

The CLUE-s model provides the probability of regional land use change using their spatial distributions. The method computes land use change incorporating socioeconomic and biophysical driving factors based on system theory. The model predicts the change in land conditions in design scenarios. The structure of a model can be sub-divided into a non-spatial demand module and a spatially explicit allocation procedure. The non-spatial module calculates the area change for all land use types at the aggregate level. For the land use demand module, different model specifications are possible, ranging from simple trend extrapolations to complex economic models. The results from the demand module need to specify the area covered annually by different land use types, which is a direct input for the allocation module. The CLUE-s model, which allows scale and context specifications for regional applications, has considered one of most flexible and generic landuse modeling frameworks (Verburg et al. 2002). 


\subsection{HEC-HMS and WASH123D Models}

The HEC-HMS rainfall runoff model is a hydrologic model used for simulating the rainfall runoff process. The model was developed by the Hydrologic Engineering Center, U.S. Army Corps of Engineering (USACE 2000, 2008), and three major modules are included: the basin, meteorological, and control specification modules (USACE 2000). The parameters in these modules must be determined in advance to implement the rainfall runoff simulations. In this study, the Soil Conservation Service (SCS) Curve Number method is selected to calculate the sub basin loss in the basin module. The parameters for initial loss, $\mathrm{CN}$ (Curve Number) value, and impervious percentage of study area are regressed based on field measurements. The SCS Unit Hydrograph Method is applied to calculate sub basin routings, and the discharge lag time is calculated using statistics from historical records. For the meteorological module, the HECHMS provides multiple options for providing the rainfall distribution in the basin. This study used the rainfall station weighting method and provided the weights for various sub watershed control rainfall stations based on Thiessen polygons. The control specification module sets the time interval for the simulations, in which $15 \mathrm{~min}$ and $1 \mathrm{~h}$ intervals are commonly used.

The WASH123D numerical model is utilized to simulate the variability in river and ground water levels. The watershed system is conceptualized as a 1-D river network, 2-D overland region, and 3-D subsurface media. The model was originally developed by Yeh et al. (1998) to cover dendritic river/stream/canal networks, overland regime, and subsurface media, including the vadose and saturated zones. The WASH123D numerical model is selected as the most appropriate protocol for this hydrology research because it simulates the flow of various component systems or combinations of component systems that comprise a watershed. Moreover, it can handle the problems related to various spatial and temporal scales, as long as the continuum assumptions are valid. To conduct efficient simulations, the following simulated options are adopted in this study: the cross section-averaged 1-D diffusive wave equation, depthaveraged 2-D diffusive wave equation, and 3-D Richards equation. The equations are solved with semi-Lagrangian and Galerkin finite element methods to determine canal network, overland, and variably saturated subsurface flows (Yeh et al. 2011). Adequate data regarding initial conditions are obtained either from measurements or simulations of steady-state versions for the boundary settings.

\section{MODELING CONFIGURATIONS}

The Fengshan Creek basin in Taiwan is selected for this study, shown in Fig. 1. The Fengshan Creek originates from Najie Mountain at an altitude of $1320 \mathrm{~m}$. Its trunk stream is approximately $45.45 \mathrm{~km}$ long, and the catchment area is $250.1 \mathrm{~km}^{2}$. Based on historical statistics, the annual rainfall ranges from $1754-2715 \mathrm{~mm}$, and annual runoff is about 376 million $\mathrm{m}^{3}$. The site is important because it is located in Hsinchu County, which includes one of the most important science parks in Taiwan. In addition, the hillside in the Fengshan basin has been subjected to excessive land reclamation and golf course construction over the past few decades. Hydrological records include flow measurements at the Xinpu Bridge station since 1970 and more than 30 years of rainfall records (1980 to present) collected at the Xinpu and Guanxi stations. The latest land use map is

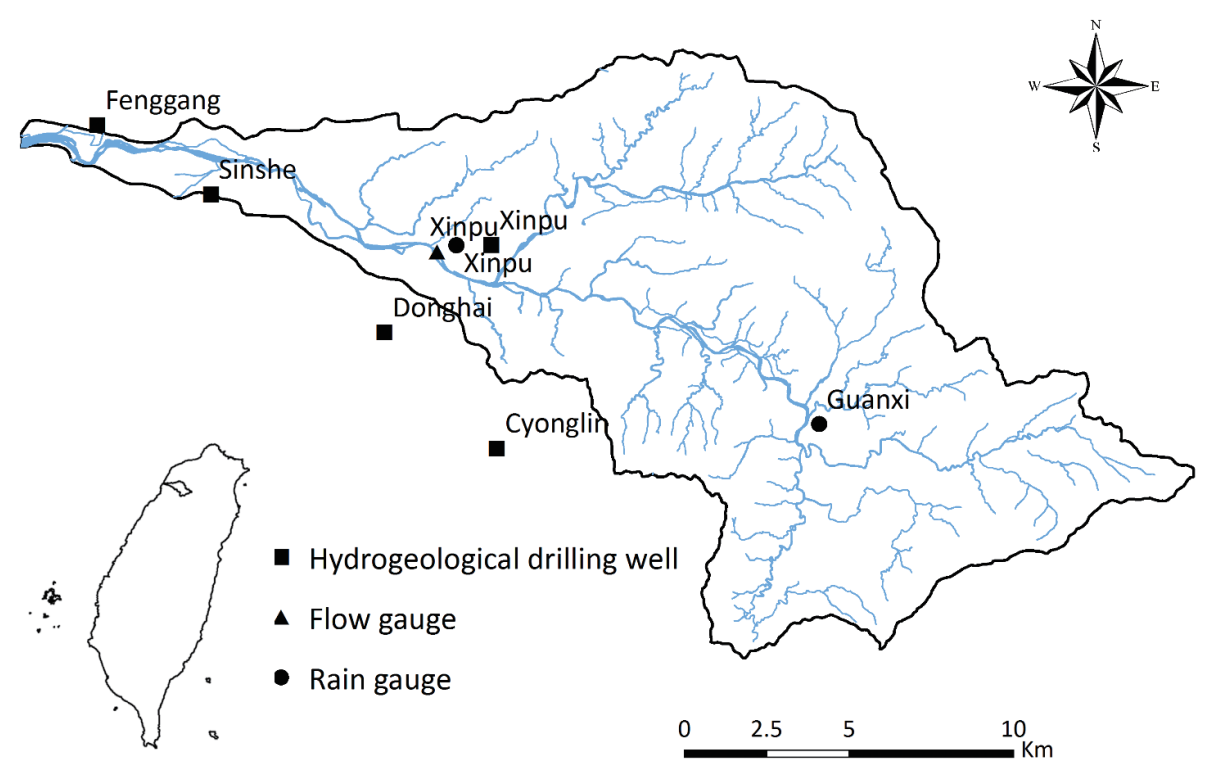

Fig. 1. Fengshan Creek basin. 
obtained from the National Land Surveying and Mapping Center, Ministry of Interior, Taiwan (NLSC). It is classified into six coverage groups, and the proportion of land use compared to the total area in Fengshan Creek basin is listed in Table 1. The agricultural and forest cover the largest areas in the watershed, accounting for $76 \%$ of the overall area. According to the geology and hydrostratigraphy investigations by Central Geological Survey (CGS), MOEA, Taiwan, the upstream of Fengshen Cekk basin belongs to Tamaopu conglomerate, which is mainly composed of conglomerate. Chaochin member of Yangmei formation made up by sandstone and shale with lower permeability are included. Other materials, e.g., general alluvia layer, channel fill deposits, Tientzhu formation, and Terrsce formation, are also interspersed among watershed.

The watershed modeling structure using the SCS curve method and WASH123D is shown in Fig. 2. The HECHMS is used to estimate discharges from zones A and B for the mountainous regions of the Fengshan Creek basin. Then the WASH123D model is applied to simulate water flow among river, overland, and subsurface at the study site of zone C. Discharges generated by zones A and B are treated as boundary force of upstream and lateral flow for river routing of WASH123D. The initial river stage is applied at the river interfacial nodes to generate boundary condition for the steady-state subsurface flow simulation. The solutions then serve as the initial conditions for the subsequent transient simulations in the coupled 1-D, 2-D, and 3 -D modeling. The 2-D ground domain is assumed to be initially dry for all case runs. Zero depth and fixed pressured head depended boundary conditions are assigned in 2-D and 3-D simulations respectively. More details can be obtained in Shih and Yeh (2011). The 1-D river is constructed using cross sections, which are taken from field geometry measured by the Water Resource Agency of Taiwan (Second River Management Office). The 2-D surface grid settings utilize non-uniform meshes, which are constructed using triangular surface elements. The triangular prism meshes for the 3-D groundwater uses the 2-D grid as its surface layer. Finally, the core data from different well sites, taken from CGS, MOEA, Taiwan, are applied to build the 3-D groundwater layers. The reference data for the underground hydrogeology profiles are obtained from wells scattered throughout the Fengshan Creek basin, shown on Fig. 1. In total, there are 61340 grids, 106371 elements, and 9 layers that comprise the underground grids, see on the hydrogeology classification of Fig. 3.
To determine the appropriate modeling parameters, a whole year of simulations for 2013 is conducted to adjust model parameters. Periods from January to May of 2014, July to October of 2014, and April to October of 2015 are used to validate modeling performance. These periods are used because some observation data is missing in 2014 and 2015. The simulated parameters for the SCS curve method, including initial loss, curve numbers, non-infiltration areas, and runoff lag time, are determined based on the geographic properties of area statistical regressions. The calculated curve numbers and non-infiltration covers are determined using land cover survey data. The results are shown in Table 2. The Manning's coefficients (Mn) for the river are determined based on the cross sectional geometry. The Mn for land surfaces are classified based on the land coverages, in which non-metropolitan areas, metropolitan areas, and others are classified. To improve the Mn for the WASH123D model, simulations of river and overland flow are conducted to adjust values. Initial values are based on field investigations (Second River Management Office, Water Resource Agency 2013), previous literature (Shih et al. 2012a). Then, we use trial and error adjustments to tune the results. Surface and groundwater simulations are combined to calibrate the saturated hydraulic conductivity $\left(\mathrm{K}_{\mathrm{s}}\right)$ in the subsurface medium. The soil retention curves for the unsaturated zone are generated using the power-law related model, and assume that the saturated hydraulic conductivity of the 3-D subsurface flow in the horizontal direction is 10 times that in the vertical direction (Shih et al. 2012a). Values range from $10^{-3}$ to $10^{-8}$. These parameters are shown in Table 3 .

\section{RESULTS AND DISCUSSIONS}

\subsection{Model Calibration/Validation}

The calibration results reveal a reasonable hydrograph for river stage and groundwater level compared to the observations at Xinpu station, as illustrated in Fig. 4. It shows the river stage during early July which Taiwan is suffered by Typhoon Soulik (2013), see on Fig. 4a. And Fig. 4b presents the groundwater level in whole year simulations for 2013. It can be seen that two extreme rainfall events in July and August, the simulated results are in agreement with observations for both the rising and receding limbs of groundwater levels as extreme rainfall occurred. Simulation results of groundwater level further indicate a Nash-Sutcliffe model efficiency coefficient (CE) is over 0.49 , indicating that the simulated and observed data have high positive correlations.

Table 1. Status quo land use coverage in Fengshan Creek basin.

\begin{tabular}{c|cccccc}
\hline & Agricultural & Forestry & Traffic & Water & Buildings & Other \\
\hline Area $\left(\mathrm{km}^{2}\right)$ & 57.3 & 133.8 & 8.8 & 7.8 & 15.9 & 27.6 \\
Coverage $(\%)$ & 22.8 & 53.3 & 3.5 & 3.1 & 6.3 & 11.0 \\
\hline
\end{tabular}




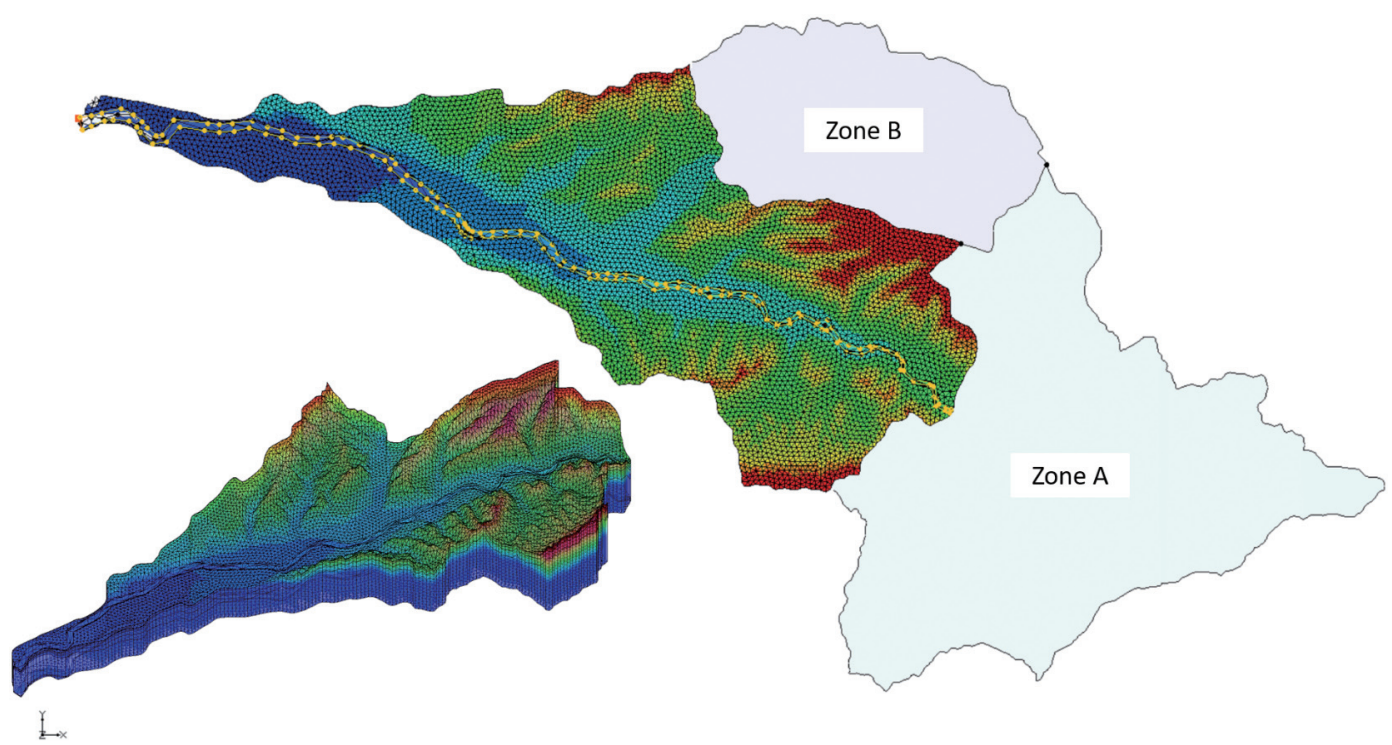

Fig. 2. Modeling zones (A and B) in HEC-HMS and grid constructions of WAH123D.

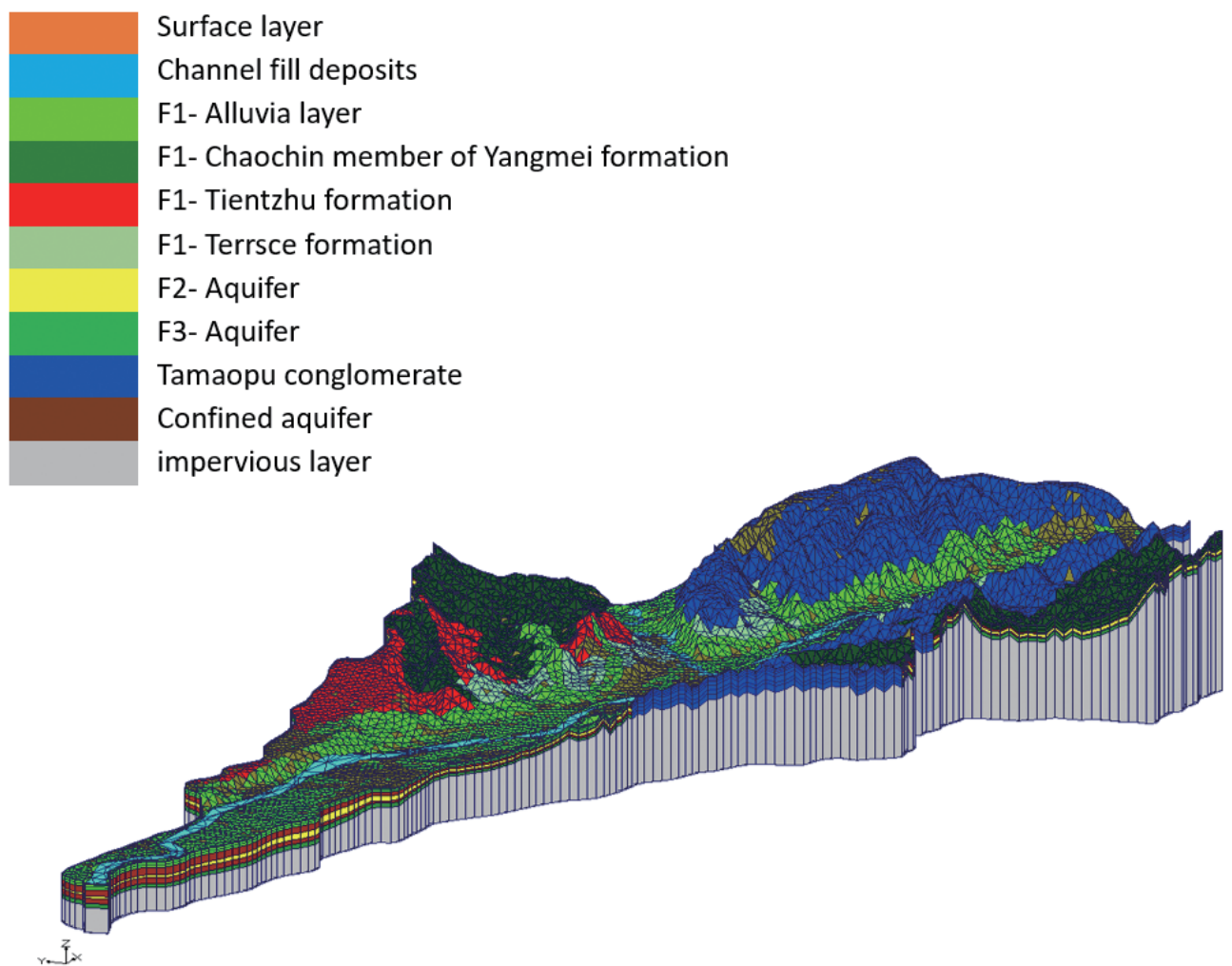

Fig. 3. Hydrogeology classifications of Fengshan Creek basin.

Table 2. Parameters used in the SCS curve method for Fengshan Creek basin.

\begin{tabular}{c|cccc}
\hline & Initial loss (mm) & Non-infiltration covers (\%) & Lag time (min.) & CN (I) \\
\hline Zone A & 4.0 & 17.6 & 131.2 & 57.9 \\
Zone B & 4.0 & 22.1 & 147.2 & 61.1 \\
\hline
\end{tabular}


Table 3. Parameters used in the WASH123D model for Fengshan Creek basin.

\begin{tabular}{ccc}
\hline Channels (1-D) $\boldsymbol{M n}$ & Surface land (2-D) $\mathbf{M n}$ & Groundwater Layers (3-D) $\mathbf{K} \boldsymbol{s}\left(\mathbf{m ~ s}^{-1}\right)$ \\
\hline & & Gravel $\left(1 \times 10^{-3}\right)$ \\
& Metropolitan $(0.120)$ & Mud or fine silt $\left(4 \times 10^{-6}\right)$ \\
$0.036-0.029$ & Non-metropolitan $(0.280)$ & River sediment $\left(2 \times 10^{-5}\right)$ \\
& Other $(0.085)$ & Aquifers $\left(1 \times 10^{-3} \sim 1 \times 10^{-5}\right)$ \\
& & Impermeable layer $\left(1 \times 10^{-8}\right)$ \\
\hline
\end{tabular}
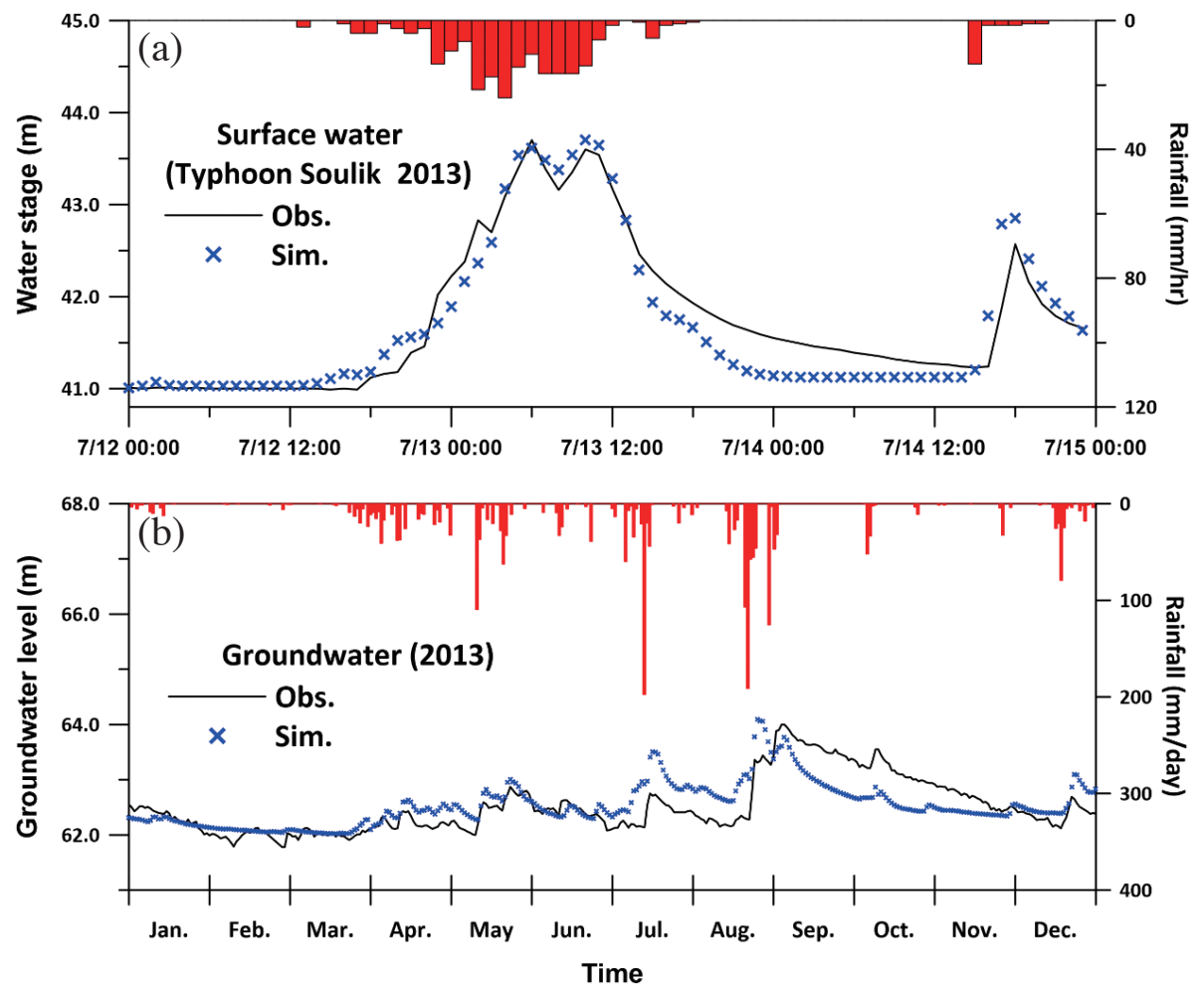

Fig. 4. Calibration results on (a) river stage and (b) groundwater level.

Essentially, an efficiency of $1(\mathrm{CE}=1)$ corresponds to a perfect match of modeled result to the observed data. Moreover, the RMSE value is $0.36 \mathrm{~m}$, which implies that the average modeling errors are very small. River stages during Typhoon Soulik (2013) is examined. Simulated hydrograph compared to observed data are shown in Fig. 4a, in which the $\mathrm{R}^{2}$, RMSE and CE is $0.910,0.253 \mathrm{~m}$, and 0.895 respectively. The simulations of surface water reveal very minor inconsistencies with the observations on the rising and receding limbs, and the modeling results also match the measured flow peak very well. It indicates that using WASH123D to implement interactions between surface and groundwater is applicable. And surficial rainfall induced groundwater level change can be reasonably assessed. In summary, the simulated hydrograph and error indicators both signify the high quality of the calibration.

Given the accuracy of the calibration, the modeling settings for all parameters are fixed and a model validation is conducted. The simulation results compared to observation data are shown in Fig. 5 for the three periods from 2014 2015. As shown, the simulated hydrograph agrees well with the observations; the $\mathrm{R}^{2}$ is 0.5 , and the RMSE is $0.21 \mathrm{~m}$. The simulated hydrograph indicated small discrepancies from the observed data, but the general trends are comparable. For example, the groundwater level in 2014 and 2015 is slightly lower compared to 2013 in the observations, and the simulations showed the same behavior in these periods. Figure 6 illustrated the hydrograph from February $06^{\text {nd }}$ to $16^{\text {th }}$ of 2014. It can be clearly seen that flow pattern between river stage and groundwater level is different. River stage rises and descend to accompany with precipitation. However, groundwater level increase with a time lag to rainfalls. It reveals about $20 \mathrm{~h}$ lag to heavy rainfalls. Flow velocity induced flow pattern between surface and groundwater is apparently identified. Therefore, these parameters are suitable for use in the hydrological models. 

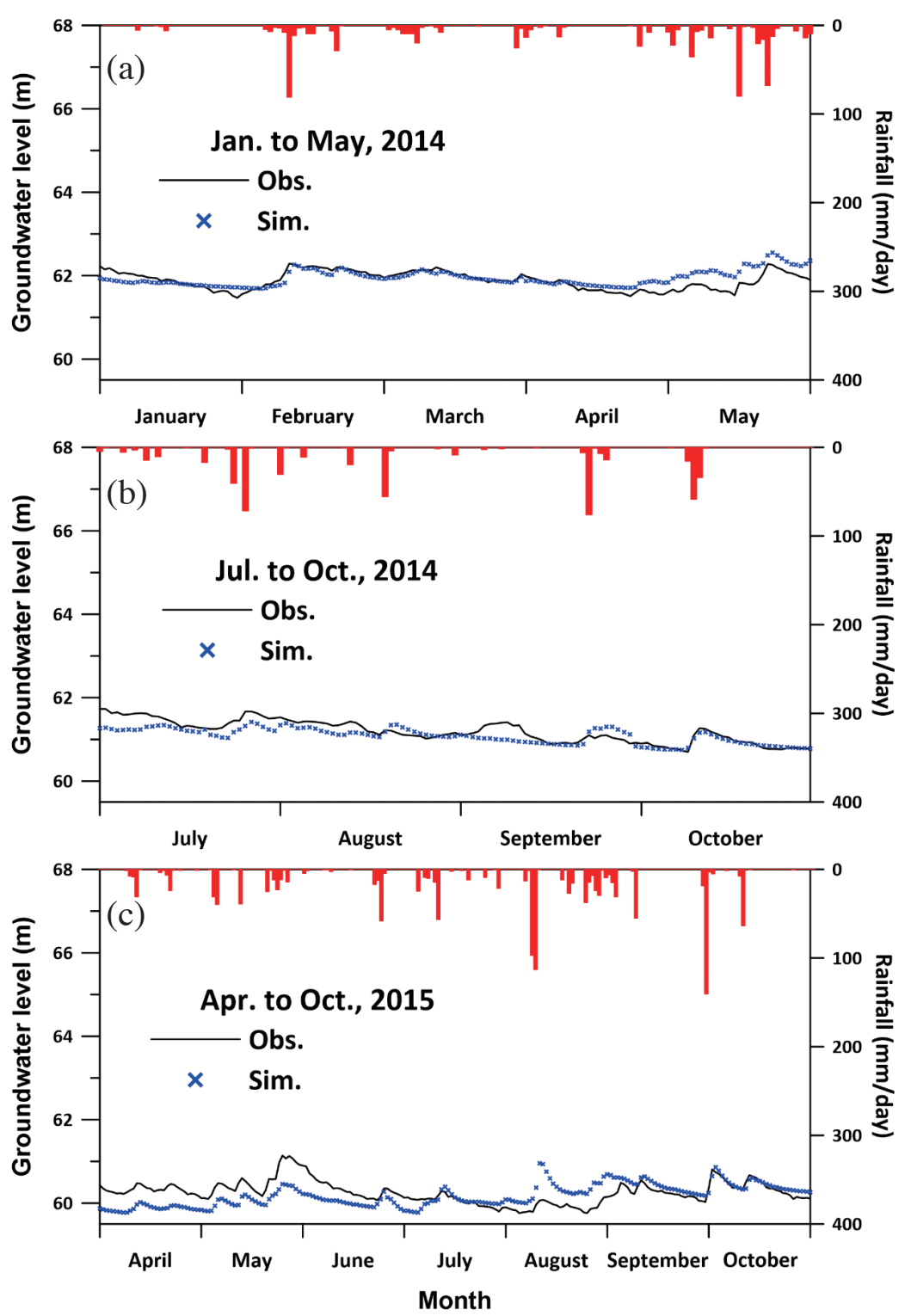

Fig. 5. Validation results of groundwater level for periods (a) January to May 2014, (b) July to October 2014, and (c) April to October 2015.

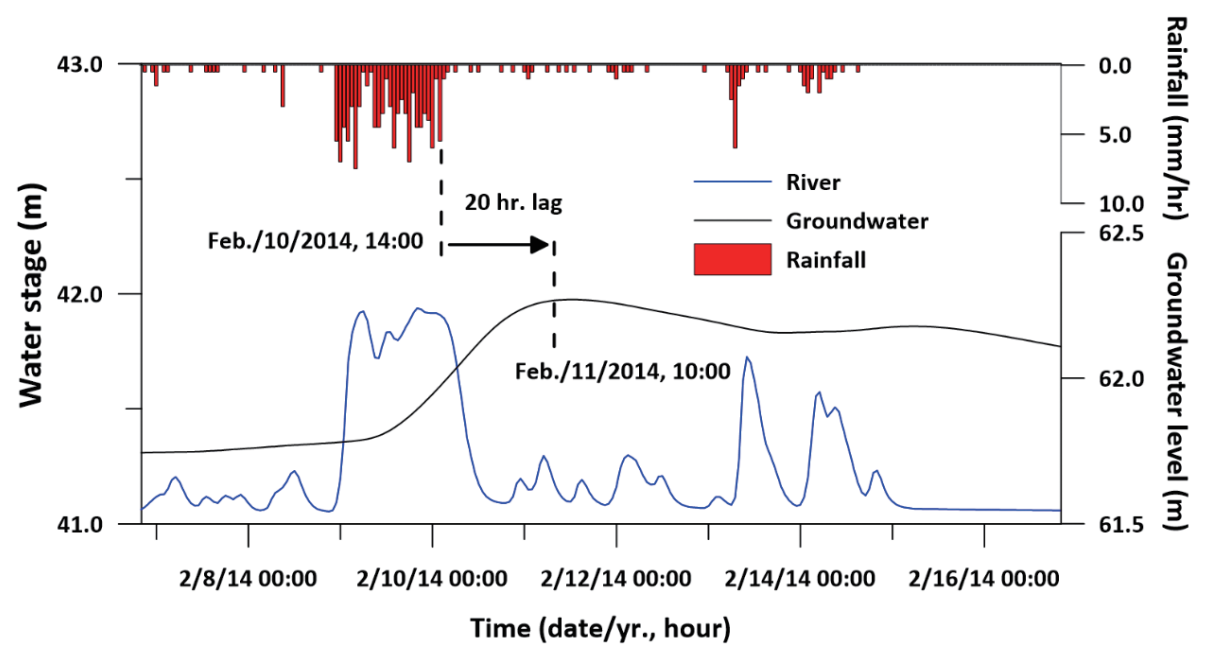

Fig. 6. Simulation of flow lag between surface and groundwater level. 


\subsection{Scenario Discussions}

Three future land coverage scenarios are generated using the CLUE-s model. To evaluate the developing processes of the Fengshan Creek basin, land-cover use investigation maps taking place on the year of 1995 and 2007 are adopted, which is the latest available data for this site. Three assumed scenarios (Wu 2014) are applied: (1) unrestrained development, wherein future site development behavior is based entirely on current city growth; (2) hillside forest conservation as a space-constrained development area, so urbanization is more apparent; and (3) limitations in building development when the average slope is greater than $30 \%$, which concentrates city development in the metropolitan area. The details for each scenario are listed in Table 4 . Results indicate that these three scenarios have very similar growth patterns, even almost identical. This is due to the lack of variability in the metropolitan area land coverage over the past decades. Only some local developments have been conducted. To simplify subsequent simulations, Scenario 1 is adopted.

In the IPCC fifth Assessment Report (2014), the Representative Concentration Pathways (RCPs) were used to project the increase of radiative forcing due to the enhancement of greenhouse effect. They describe four possible climate futures, all of which are considered possible depending on the amount of greenhouse gases concentrations in the years to come. Four RCPs (i.e., RCP2.6, RCP4.5, RCP6.0, and $\mathrm{RCP} 8.5$ ) are named after a possible range in radiative forcing values in the year 2100 relative to pre-industrial values $\left(+2.6,+4.5,+6.0\right.$, and $+8.5 \mathrm{~W} \mathrm{~m}^{-2}$, respectively). The RCP2.6 scenario was adopted for our preliminary studies. In short, hydrological measurements from Xinpu and Guanxi station were applied as baseline data for comparisons with climate scenarios. WGEN stochastic weather generator is applied to produce daily precipitation, minimum/maximum temperature, and solar radiation with downscaled data, provided by the TCCIP, in near future, future, and distant future. Arithmetic average of above three time periods are shown in Table 5. In general, the wet season in Taiwan lasts from May to October. The projection of RCP2.6 scenario indicate that temperature has an increasing trend, and the rainy season will get wetter and the dry season will get drier.

Modeling hydrological response including the future climate scenarios described previously, near future, future, and distant future, and land cover changes (Scenario 1) are then implemented. Modeling results between river stage and groundwater level change, and their percentage variance at the location of Xinpu station are drawn in Figs. 7 and 8 respectively. In which the variance is calculated using simulations of water levels of future scenarios divide state quo climate scenario. A spatial and temporal interpolation of thiessen polygons method is applied. In which precipitation on Xinpu and Guanxi station were generated by climate models. Simulations show a slightly increas- ing trend for river levels in the future, as shown in Fig. 7a; the monthly mean river levels increase slightly, averaging about $0.10 \mathrm{~m}$. We then calculate the river level variability and compare it to the current climate scenario simulation; the difference is expressed in percentage and illustrated in Fig. 7b. Simulations show the monthly mean river level decreases $0.6 \mathrm{~m}$ in the dry season, and increases $0.15 \mathrm{~m}$ in wet season. Discharge of river is also estimated, see on Table 6. Monthly mean of river flow has no significant difference in designed future scenarios. To calculate discharge on wet and dry seasons separately, simulation results show that discharge decreases $0.09,0.51$, and $0.55 \mathrm{cms}$ in the dry season of near future, future, and distant future respectively. For wet season, it increases 1.02, 1.29, and $2.02 \mathrm{cms}$ of near future, future, and distant future respectively. As shown, it is clearly seen that water resource becomes wetter in the wet season and drier in the dry season; the two seasons show contrasting results. Moreover, rainfall distribution of Taiwan is characterized as non-uniform in time and space, and the slope of rivers are very steep. That results in the watersheds become getting difficult to store rain water. Although rainfall has identified slightly increased under future scenarios, it seems barely to contribute to river discharges. In summary, the combination of future land use with various future climate changes does not apparent affect the annual water level of the river. However, the water resource in the dry and wet seasons more clearly diverge, with increasing amplitude in their variance.

Simulations of groundwater level and variance percentages are shown in Fig. 8, in which variances are calculated the same as those in Fig. 7. The monthly mean groundwater levels increase an average of $0.60 \mathrm{~m}$ in the dry season and $1.2 \mathrm{~m}$ in the wet season, as shown in Fig. 8a. In comparison to status quo groundwater levels (Fig. 8b), the variance between different climate scenarios (near future, future, and distant future) in the dry season indicate a reduction of $9.69,17.71$, and $20.40 \%$, respectively; in the rainy season, groundwater levels increase $1.30,3.23$, and $7.99 \%$, respectively, in the near future, future, and distant future. That can be clearly seen that the future rainfall will become heavier in the wet season and drier in the dry season. It is no question that less rainfall will lead to groundwater drawn down while dry season. To the raining season, although rainfall is increased, slope of riverbed in most watershed of Taiwan is steep. That will result in rainfall induced surface runoff infiltrate underground inefficiently. That is the reason of climate change has larger impacts on groundwater than surface water. In summary, groundwater levels have a slightly increasing trend given the future climate and land cover changes in the Fengshan Creek basin. Furthermore, the seasonal variation will be amplified, with lower groundwater levels in the dry season and higher levels in the wet season.

In this study, simulations indicate that the hydrological changes are mainly influencing groundwater rather than 
surface water. To better understand the spatial distribution of the groundwater changes in the future, we take the difference between groundwater levels under status quo and future dry season conditions; the results are shown in Fig. 9. In the flat regions of the watershed, future groundwater level changes vary between -20 and $0 \mathrm{~cm}$. In contrast, there is a signifi- cant decline in groundwater levels in the mountainous region, with some data indicating $>60 \mathrm{~cm}$ decreases compared to the seasonal average. In short, the groundwater levels in mountainous regions show a more significant decrease than lower elevation flat areas in the Fengshan Creek basin under future climate and land cover conditions.

Table 4. Scenarios for land cover change based on CLUE-s.

\begin{tabular}{c|ccc}
\hline & Scenario 1 & Scenario 2 & Scenario 3 \\
\hline Non-metropolitan areas (\%) & 77.42 & 77.45 & 77.49 \\
Metropolitan areas (\%) & 13.59 & 13.46 & 13.44 \\
Other regions (\%) & 8.99 & 9.09 & 9.07 \\
\hline
\end{tabular}

Table 5. Arithmetic means of near future, future, and distant future of temperature and rainfall under the RCP2.6 scenario.

\begin{tabular}{c|cccccccccccc}
\hline & Jan. & Feb. & Mar. & Apr. & May & Jun. & Jul. & Aug. & Sep. & Oct. & Nov. & Dec. \\
\hline Temp. $\left({ }^{\circ} \mathrm{C}\right)$ & 0.76 & 0.63 & 0.68 & 0.57 & 0.75 & 0.67 & 0.69 & 0.71 & 0.60 & 0.46 & 0.64 & 0.64 \\
Rainfall $(\%)$ & 2.16 & -0.26 & -4.67 & -2.42 & -3.88 & 3.91 & 12.21 & 11.41 & 6.19 & -6.31 & 4.69 & -6.48 \\
\hline
\end{tabular}
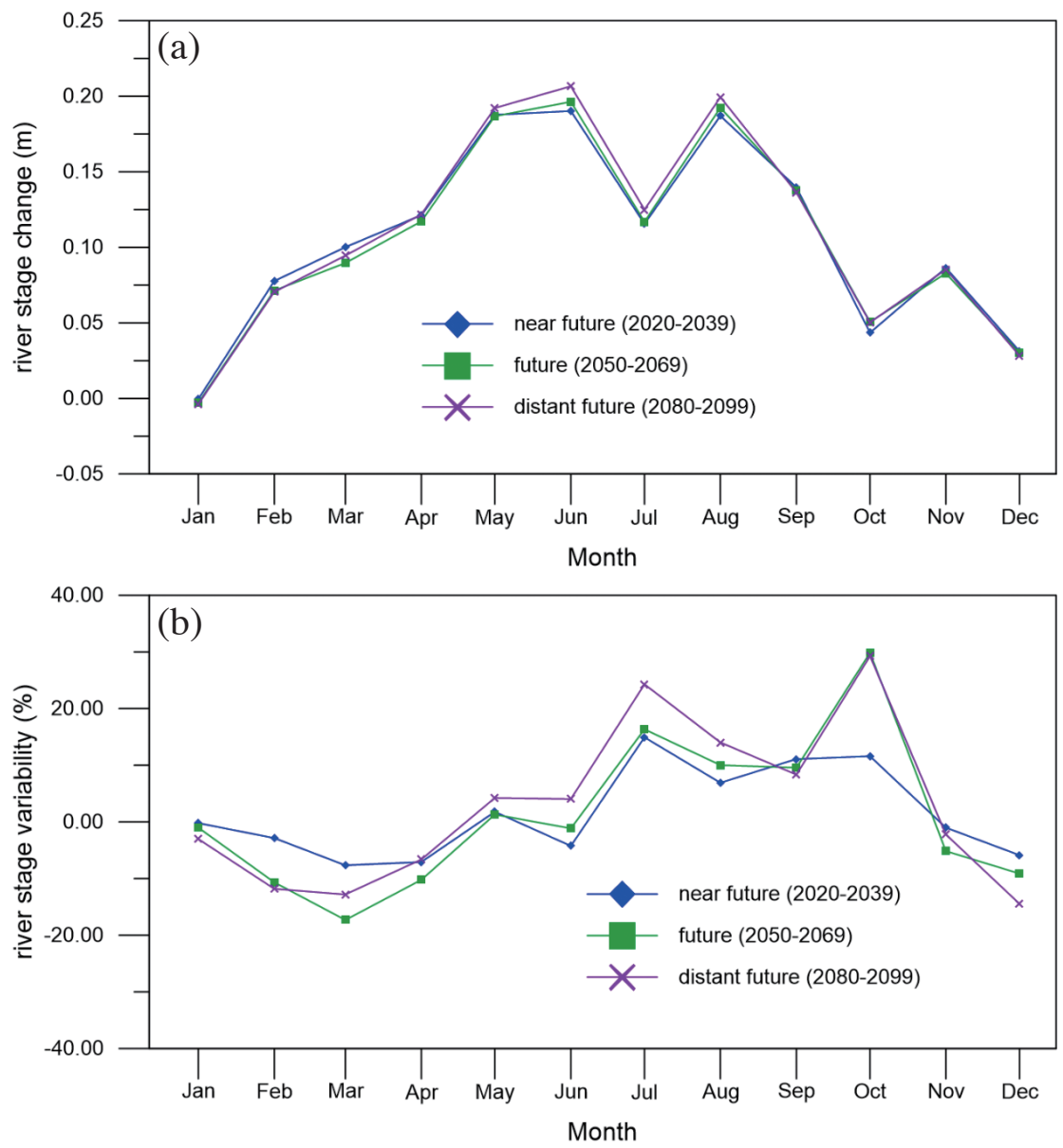

Fig. 7. Modeling results using future land cover and climate scenarios for (a) river stage change and (b) their percentage variance. 

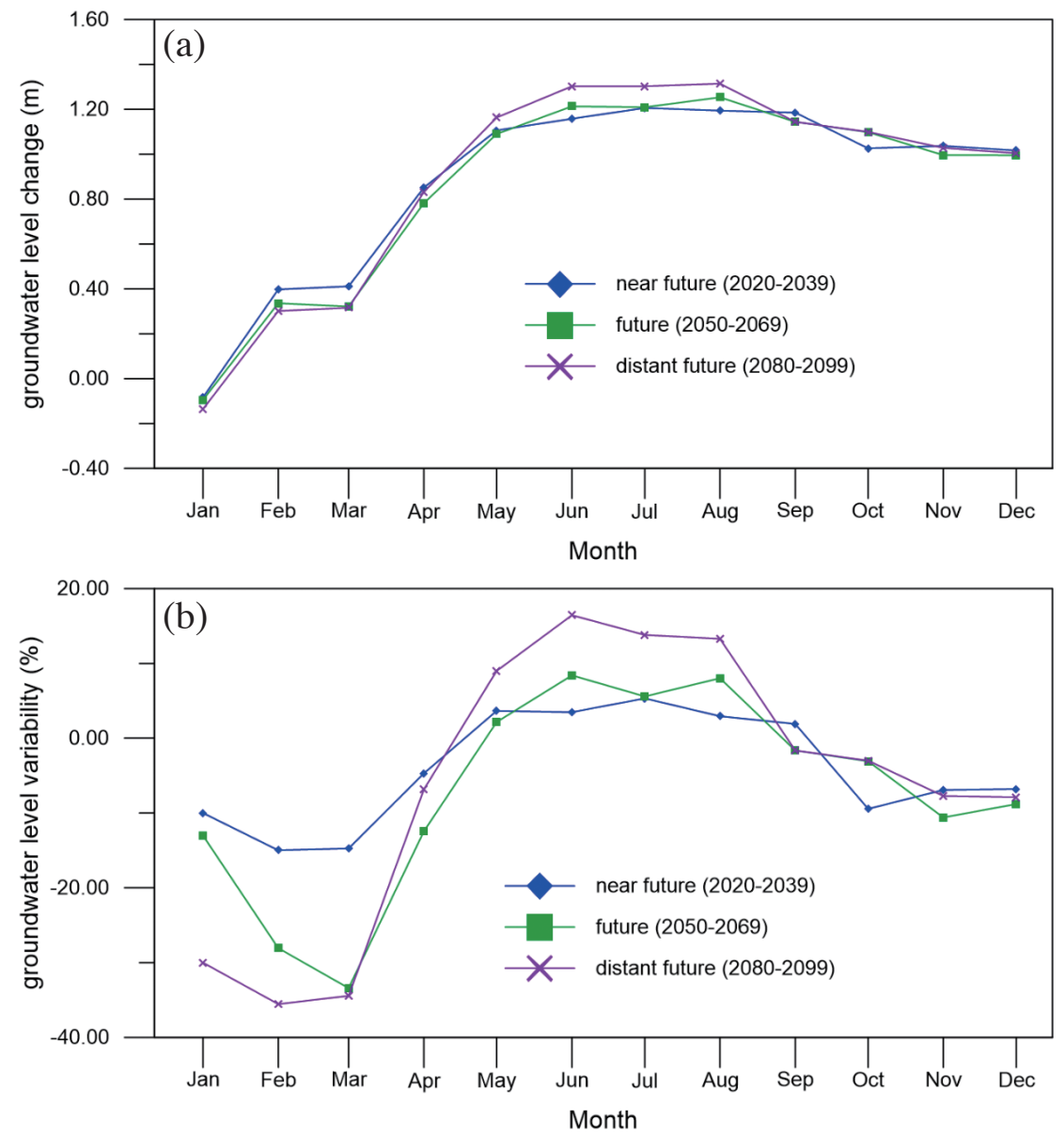

Fig. 8. Modeling results using future land cover and climate scenarios for (a) groundwater level change and (b) their percentage variance.

Table 6. Simulation of river flow under future climate (unit: $\mathrm{cms}$ month $\left.^{-1}\right)$.

\begin{tabular}{c|ccc}
\hline & near future & future & distant future \\
\hline monthly mean & 0.41 & 0.32 & 0.53 \\
dry season mean & -0.09 & -0.51 & -0.55 \\
raining season mean & 1.02 & 1.29 & 2.02 \\
\hline
\end{tabular}

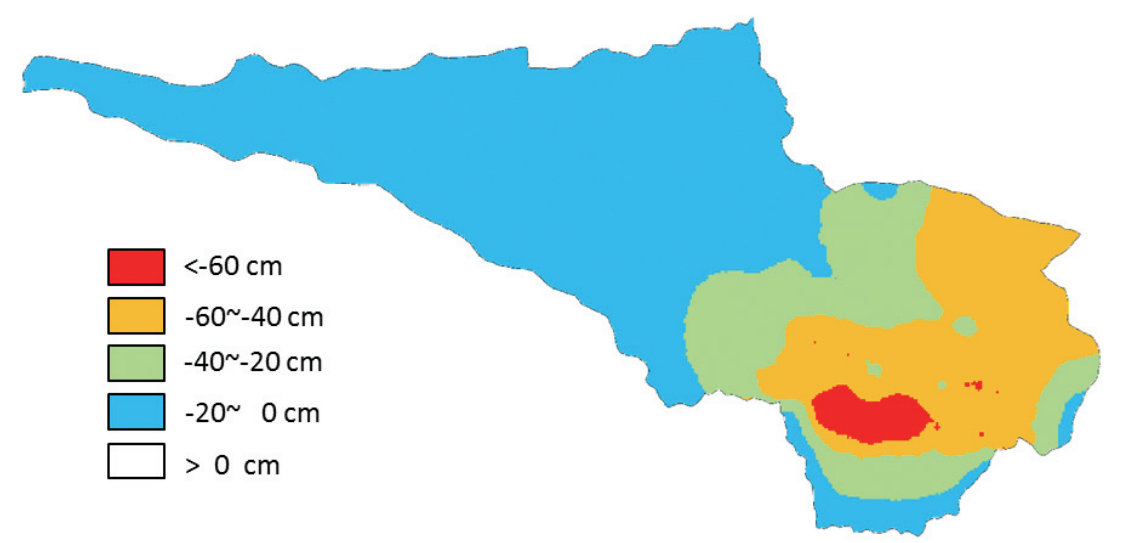

Fig. 9. Spatial distribution of changes in groundwater level under future climate (RCP2.6) and land cover (Scenario 1) conditions. 


\section{CONCLUSION}

This study proposed a method to use WGEN and GCM models to generate meteorological data, the CLUE-s model to predict land cover changes, the HEC-HMS rainfall runoff model to calculate watershed discharge, and the WASH123D model to simulate hydrological effects under future climate and land cover conditions. Simulation results suggest that the effects of climate change are more relevant compared to local land cover changes in this study region. Both river stage and groundwater level tend to slightly increase in future climate and land coverage scenarios. However, the seasonal differences are amplified, and groundwater levels are drier in the dry season and wetter in the wet season. Furthermore, there are spatial differences under future climate projections; the groundwater levels in the mountainous region will decline more than in the flat regions of the Fengshan Creek basin.

Acknowledgements This research is founded by the Ministry of Science and Technology, Taiwan, under Grant no. MOST-104-2621-M-005-007.

\section{REFERENCES}

Akhtar, M., N. Ahmad, and M. J. Booij, 2008: The impact of climate change on the water resources of Hindukush-Karakorum-Himalaya region under different glacier coverage scenarios. J. Hydrol., 355, 148-163, doi: 10.1016/j.jhydrol.2008.03.015. [Link]

Arnell, N. W. and S. N. Gosling, 2013: The impacts of climate change on river flow regimes at the global scale. J. Hydrol., 486, 351-364, doi: 10.1016/j.jhydrol.2013.02.010. [Link]

Britz, W., P. H. Verburg, and A. Leip, 2011: Modelling of land cover and agricultural change in Europe: Combining the CLUE and CAPRI-Spat approaches. Agr. Ecosyst. Environ., 142, 40-50, doi: 10.1016/j. agee.2010.03.008. [Link]

Chen, X., K. Alizad, D. Wang, and S. C. Hagen, 2014: Climate change impact on runoff and sediment loads to the Apalachicola River at seasonal and event scales. $J$. Coast. Res., 68, 35-42, doi: 10.2112/si68-005.1. [Link]

Déqué, M., D. P. Rowell, D. Lüthi, F. Giorgi, J. H. Christensen, B. Rockel, D. Jacob, E. Kjellström, M. de Castro, and B. van den Hurk, 2007: An intercomparison of regional climate simulations for Europe: Assessing uncertainties in model projections. Clim. Change, 81, 53-70, doi: 10.1007/s10584-006-9228-x. [Link]

Easterling, D. R., G. A. Meehl, C. Parmesan, S. A. Changnon, T. R. Karl, and L. O. Mearns, 2000: Climate extremes: Observations, modeling, and impacts. Science, 289, 2068-2074, doi: 10.1126/science.289.5487.2068. [Link]
Guo, S., J. Wang, L. Xiong, A. Ying, and D. Li, 2002: A macro-scale and semi-distributed monthly water balance model to predict climate change impacts in China. J. Hydrol., 268, 1-15, doi: 10.1016/s00221694(02)00075-6. [Link]

Hallegatte, S., C. Green, R. J. Nicholls, and J. Corfee-Morlot, 2013: Future flood losses in major coastal cities. Nat. Clim. Change, 3, 802-806, doi: 10.1038/nclimate 1979. [Link]

Halwatura, D. and M. M. M. Najim, 2013: Application of the HEC-HMS model for runoff simulation in a tropical catchment. Environ. Model. Software, 46, 155-162, doi: 10.1016/j.envsoft.2013.03.006. [Link]

Hay, L. E., S. L. Markstrom, and C. Ward Garrison, 2011: Watershed-scale response to climate change through the twenty-first century for selected basins across the United States. Earth Interact., 15, 1-37, doi: 10.1175/2010EI370.1. [Link]

Hovenga, P. A., D. Wang, S. C. Medeiros, S. C. Hagen, and K. Alizad, 2016: The response of runoff and sediment loading in the Apalachicola River, Florida to climate and land use land cover change. Earth's Future, 4, 124-142, doi: 10.1002/2015EF000348. [Link]

Hsu, H. H., C. Chou, Y. C. Wu, M. M. Lu, C. T. Chen, and Y. M. Chen, 2011: Climate Change in Taiwan: Scientific Report 2011 (Summary), National Science Council, Taipei, Taiwan, ROC, 67 pp.

Hsu, T. W., D. S. Shih, and W. J. Chen, 2015: Destructive Flooding Induced by Broken Embankments along Linbian Creek, Taiwan, during Typhoon Morakot. J. Hydrol. Eng., 20, doi: 10.1061/(ASCE)HE.19435584.0001069. [Link]

Hurkmans, R. T. W. L., W. Terink, R. Uijlenhoet, E. J. Moors, P. A. Troch, and P. H. Verburg, 2009: Effects of land use changes on streamflow generation in the Rhine basin. Water Resour. Res., 45, W06405, doi: 10.1029/2008WR007574. [Link]

IPCC, 2008: Appendix A to the principles governing IPCC work. Procedures for the Preparation, Review, Acceptance, Adoption, Approval and Publication of IPCC Reports, Intergovernmental Panel on Climate Change (IPCC). Available at http://www.ipcc.ch/organization/ organization procedures.shtml.

IPCC, 2013: Summary for Policymakers. In: Stocker, T. F., D. Qin, G.-K. Plattner, M. Tignor, S. K. Allen, J. Boschung, A. Nauels, Y. Xia, V. Bex, and P. M. Midgley (Eds.), Climate Change 2013: The Physical Science Basis, Contribution of Working Group I to the Fifth Assessment Report of the Intergovernmental Panel on Climate Change, Cambridge University Press, Cambridge, United Kingdom and New York, NY, USA.

Kling, H., P. Stanzel, and M. Preishuber, 2014: Impact modelling of water resources development and climate scenarios on Zambezi River discharge. J. Hydrol., 1, 
17-43, doi: 10.1016/j.ejrh.2014.05.002. [Link]

Lin, Y. P., N. M. Hong, P. J. Wu, C. F. Wu, and P. H. Verburg, 2007: Impacts of land use change scenarios on hydrology and land use patterns in the $\mathrm{Wu}-\mathrm{Tu}$ watershed in Northern Taiwan. Landsc. Urban Plann., 80, 111126, doi: 10.1016/j.landurbplan.2006.06.007. [Link]

Menzel, L., A. H. Thieken, D. Schwandt, and G. Bürger, 2006: Impact of climate change on the Regional hydrology - Scenario-based modelling studies in the German Rhine catchment. Nat. Hazards, 38, 45-61, doi: 10.1007/s11069-005-8599-z. [Link]

Minville, M., F. Brissette, and R. Leconte, 2008: Uncertainty of the impact of climate change on the hydrology of a nordic watershed. J. Hydrol., 358, 70-83, doi: 10.1016/j.jhydrol.2008.05.033. [Link]

Park, J.-Y., M.-J. Park, H.-K. Joh, H.-J. Shin, H.-J. Kwon, R. Srinivasan, and S.-J. Kim, 2011: Assessment of MIROC3.2 HiRes Climate and CLUE-s Land Use Change Impacts on Watershed Hydrology Using SWAT. Transactions of the ASABE, 54, 1713-1724, doi: 10.13031/2013.39842. [Link]

Pickering, N. B., J. R. Stedinger, and D. A. Haith, 1988: Weather input for nonpoint-source pollution models. J. Irrig. Drain. Eng., 114, 674-690, doi: 10.1061/ (ASCE)0733-9437(1988)114:4(674). [Link]

Prudhomme, C. and H. Davies, 2008: Assessing uncertainties in climate change impact analyses on the river flow regimes in the UK. Part 2: Future climate. Clim. Change, 93, 197-222, doi: 10.1007/s10584-008-94616. [Link]

Richardson, C. W., 1981: Stochastic simulation of daily precipitation, temperature, and solar radiation. Water Resour. Res., 17, 182-190, doi: 10.1029/ WR017i001p00182. [Link]

Semenov, M. and R. Brooks, 1999: Spatial interpolation of the LARS-WG stochastic weather generator in Great Britain. Clim. Res., 11, 137-148, doi: 10.3354/ cr011137. [Link]

Shih, D. S. and G. T. Yeh, 2011: Identified model parameterization, calibration, and validation of the physically distributed hydrological model WASH123D in Taiwan. J. Hydrol. Eng., 16, 126-136, doi: 10.1061/ (ASCE)HE.1943-5584.0000293. [Link]

Shih, D. S., J. M. Liau, and G. T. Yeh, 2012a: Model Assessments of Precipitation with a Unified Regional Circulation Rainfall and Hydrological Watershed Model. J. Hydrol. Eng., 17, 43-54, doi: 10.1061/(ASCE) HE.1943-5584.0000414. [Link]

Shih, D. S., T. W. Hsu, K. C. Chang, and H. L. Juan, 2012b: Implementing Coastal Inundation Data with an Integrated Wind Wave Model and Hydrological Watershed Simulations. Terr. Atmos. Ocean. Sci., 23, 513-525, doi: 10.3319/TAO.2012.05.03.01(WMH). [Link]

TCCIP, 2015: Taiwan Climate Change Projection and In- formation Platform (TCCIP). Available at http://tccip. ncdr.nat.gov.tw/NCDR/main/index.aspx.

Trisurat, Y., R. Alkemade, and P. H. Verburg, 2010: Projecting Land-Use Change and Its Consequences for Biodiversity in Northern Thailand. Environ. Manage., 45, 626-639, doi: 10.1007/s00267-010-9438-x. [Link]

Tung, C., 2001: Climate change impacts on water resources of the Tsengwen Creek Watershed in Taiwan. J. Am. Water Resour. Assoc., 37, 167-176, doi: 10.1111/ j.1752-1688.2001.tb05483.x. [Link]

US Army Corps of Engineers (USACE), 2000: Hydrologic Modeling System HEC-HMS: Technical Reference Manual, US Army Corps of Engineers, Hydrologic Engineering Center, Davis, CA - United States of America, 149 pp.

US Army Corps of Engineers (USACE), 2008: Hydrologic Modeling System HEC-HMS: Applications Guide, Hydrologic Engineering Center, Davis, CA - United States of America.

Veijalainen, N., E. Lotsari, P. Alho, B. Vehviläinen, and J. Käyhkö, 2010: National scale assessment of climate change impacts on flooding in Finland. J. Hydrol., 391, 333-350, doi: 10.1016/j.jhydrol.2010.07.035. [Link]

Verburg, P. H., W. Soepboer, A. Veldkamp, R. Limpiada, V. Espaldon, and S. S. Mastura, 2002: Modeling the spatial dynamics of regional land use: The CLUE-S model. Environ. Manage., 30, 391-405, doi: 10.1007/ s00267-002-2630-x. [Link]

Verburg, P. H., C. J. E. Schulp, N. Witte, and A. Veldkamp, 2006a: Downscaling of land use change scenarios to assess the dynamics of European landscapes. Agr. Ecosyst. Environ., 114, 39-56, doi: 10.1016/j. agee.2005.11.024. [Link]

Verburg, P. H., K. P. Overmars, M. G. A. Huigen, W. T. de Groot, and A. Veldkamp, 2006b: Analysis of the effects of land use change on protected areas in the Philippines. Appl. Geogr., 26, 153-173, doi: 10.1016/j. apgeog.2005.11.005. [Link]

Wang, D., S. C. Hagen, and K. Alizad, 2013: Climate change impact and uncertainty analysis of extreme rainfall events in the Apalachicola River basin, Florida. J. Hydrol., 480, 125-135, doi: 10.1016/j.jhydrol.2012.12.015. [Link]

Wassenaar, T., P. Gerber, P. H. Verburg, M. Rosales, M. Ibrahim, and H. Steinfeld, 2007: Projecting land use changes in the Neotropics: The geography of pasture expansion into forest. Global Environ. Change, 17, 86104, doi: 10.1016/j.gloenvcha.2006.03.007. [Link]

Wu, H. J., 2014: Application of Land Use Changes Model and Hydrological Model to Analyze the Impact of Hydrological Fluxes of Climate Change. Master Thesis, Department of Civil Engineering, National Central University, Taoyuan. (in Chinese) 
Wu, R. S. and D. A. Haith, 1993: Land Use, Climate, and Water Supply. J. Water Resour. Plann. Manag., 119, 685-704, doi: 10.1061/(ASCE)07339496(1993)119:6(685). [Link]

Yang, Y. C. E., P. A. Ray, C. M. Brown, A. F. Khalil, and W. H. Yu, 2015: Estimation of flood damage functions for river basin planning: A case study in Bangladesh. Nat. Hazards, 75, 2773-2791, doi: 10.1007/s11069014-1459-y. [Link]
Yeh, G. T., H. P. Cheng, J. R. Cheng, and J. H. Lin, 1998: A numerical model to simulate flow and contaminant and sediment transport in watershed systems (WASH123D). Waterways Experiment Station, Technical Rep. CHL-98-15.

Yeh, G. T., D. S. Shih, and J. R. C. Cheng, 2011: An integrated media, integrated processes watershed model. Comput. Fluid., 45, 2-13, doi: 10.1016/j.compfluid.2010.11.018. [Link] 